\title{
An Inhibitor of Macrophage Arginine Transport and Nitric Oxide Production (CNI-1493) Prevents Acute Inflammation and Endotoxin Lethality
}

\author{
Marina Bianchi,* Peter Ulrich,* Ona Bloom, ${ }^{\dagger}$ \\ Malcolm Meistrell III,* Gary A. Zimmerman,*\# \\ Helena Schmidtmayerova,* Michael Bukrinsky,* \\ Thomas Donnelley,* Richard Bucala,* Barbara Sherry,* \\ Kirk R. Manogue,* Anthony J. Tortolani, ${ }^{\dagger}$ Anthony Cerami,* \\ and Kevin J. Tracey*t \\ *The Picower Institute for Medical Research, Manhasset, New York \\ ${ }^{\ddagger}$ New York Hospital-Cornell University Medical College, New York, \\ New York, U.S.A. \\ ${ }^{\dagger}$ Laboratory of Biomedical Science, Department of Surgery, North \\ Shore University Hospital-Cornell University Medical College, \\ Manhasset, New York, U.S.A.
}

\begin{abstract}
Background: Nitric oxide (NO), a small effector molecule produced enzymatically from L-arginine by nitric oxide synthase (NOS), is a mediator not only of important homeostatic mechanisms (e.g., blood vessel tone and tissue perfusion), but also of key aspects of local and systemic inflammatory responses. Previous efforts to develop inhibitors of NOS to protect against NO-mediated tissue damage in endotoxin shock have been unsuccessful, largely because such competitive NOS antagonists interfere with critical vasoregulatory NO production in blood vessels and decrease survival in endotoxemic animals. Accordingly, we sought to develop a pharmaceutical approach to selectively inhibit NO production in macrophages while sparing NO responses in blood vessels.
\end{abstract}

Materials and Methods: The processes of cytokineinducible L-arginine transport and NO production were studied in the murine macrophage-like cell line (RAW 264.7). A series of multivalent guanylhydrazones were synthesized to inhibit cytokine-inducible L-arginine transport. One such compound (CNI-1493) was studied further in animal models of endothelial-derived relaxing factor (EDRF) activity, carrageenan inflammation, and lethal lipopolysaccharide (LPS) challenge.

Results: Upon activation with cytokines, macrophages increase transport of L-arginine to support the production of NO by NOS. Since endothelial cells do not require this additional arginine transport to produce NO, we reasoned that a competitive inhibitor of cytokine-inducible L-arginine transport would not inhibit EDRF activity in blood vessels, and thus might be effectively employed against endotoxic shock. CNI-1493, a tetravalent guanylhydrazone, proved to be a selective inhibitor of cytokineinducible arginine transport and NO production, but did not inhibit EDRF activity. In mice, CNI-1493 prevented the development of carrageenan-induced footpad inflammation, and conferred protection against lethal LPS challenge.

Conclusions: A selective inhibitor of cytokine-inducible L-arginine transport that does not inhibit vascular EDRF responses is effective against endotoxin lethality and significantly reduces inflammatory responses.

Address correspondence and reprint requests to: Kevin J.

Tracey, The Picower Institute for Medical Research,

Mannhasset, NY 11030. 


\section{INTRODUCTION}

Lethal tissue injury in septic shock syndrome, a frequent complication of critical illness, causes excessive mortality in association with any number of disease states, including trauma. Septic shock syndrome and organ damage are directly attributable to the action of endogenous mediators released by macrophages activated by pathogenic stimuli such as bacterial endotoxin (lipopolysaccharide [LPS]). These mediators include a variety of cytokines (especially tumor necrosis factor [TNF] and interleukin 1 [IL-1]) and nitric oxide (1-4). When produced in smaller physiological amounts, these factors are beneficial in host defense, but when overproduced in pathological quantities, their injurious and lethal effects predominate (5). Identification of the molecular mechanisms underlying the lethality of septic shock has led to the development of novel experimental strategies targeted against these endogenous mediators in the hope of limiting morbidity and mortality in this grave disease process.

Nitric oxide (NO) is a short-lived effector molecule that has been implicated in causing hypotension, vascular leakage syndrome, and tissue injury in septic shock (for review see Refs. 6 and 7). It is enzymatically produced from Larginine by nitric oxide synthase (NOS), an enzyme present as various inducible and constitutive isoforms in smooth muscle, neurons, endothelial cells, macrophages, and other cell types. A number of agents that competitively inhibit NOS [(e.g., $\mathrm{N}^{\mathrm{G}}$ methyl-L-Arginine (L-NMA) and $\mathrm{N}^{\mathrm{G}}$-nitro-L-arginine methyl estes (L-NAME) )] have been developed for use as anti-inflammatory agents. These have been shown to be effective in preventing, for instance, the inflammation associated with experimental adjuvant arthritis, and the development of immune complex glomerulonephritis in MRL-lpr/ lpr mice $(8,9)$. Unfortunately, these agents are deleterious when administered in experimental endotoxic shock, where they actually decrease survival relative to vehicle-treated controls (10-14). Recent evidence reveals that this increase in mortality is a side effect of the non-selective action of these compounds, which indiscriminately inhibit vital NOS activity in blood vessels (termed endothelium-derived relaxing factor [EDRF]), rather than the desired action of inhibiting macrophage-derived NO (13). As a result, local vasoconstriction cannot be relieved by EDRF, reducing blood flow to critical tissues, limiting oxygen delivery to tissues, and worsening ischemic organ damage already present during shock $(13,15)$. Thus, the presently available NOS inhibitors further compromise organ perfusion during endotoxic shock and hasten rather than allay mortality in this condition.

Based in part on these observations, there is widespread interest in the identification of experimental agents to inhibit the production of NO in macrophages and other cells, but preserve the vasoregulatory NO responses in blood vessels. In the present study, we designed and developed a novel compound that limits L-arginine uptake by macrophages and inhibits their NO production. This agent (CNI-1493) selectively inhibited cytokine-inducible L-arginine uptake in macrophages, but did not inhibit EDRF activity in vivo. Moreover, it was effective in preventing carrageenan-induced inflammation and conferred protection against endotoxin lethality. We conclude that novel compounds that inhibit cytokine-inducible $\mathrm{L}$-arginine transport activity may be effective therapeutic agents against inflammation and shock.

\section{MATERIALS AND METHODS}

\section{Synthesis of CNI-1493}

CNI-1493 (N,N' -bis[3,5-diacetylphenyl]decanediamide tetrakis[amidinohydrazone] tetrahydrochloride) was prepared by reacting 3,5-diacetylaniline (16) with sebacoyl chloride in dichloromethane containing pyridine. The resulting tetraketone was collected by filtration, and reacted with aminoguanidine hydrochloride in aqueous ethanol at reflux. The final product was purified from the reactants by crystallization, and subjected to elemental analysis, proton NMR, and melting point determinations to confirm structure and assess purity prior to use. These data indicated $\geq 98 \%$ purity, with the identity of the principal contaminant as the corresponding tris-aminohydrazone. The compound was not contaminated with detectable quantities of aminoguanidine. Material from a single synthesis was used in all the studies reported, but comparable results have been obtained from two separate preparations of the compound.

\section{Measurement of NO Synthesis by Murine Macrophages}

The murine macrophage-like cell line RAW 264.7 was obtained from ATCC, expanded, and subcultured in RPMI $\left(1 \times 10^{6}\right.$ cells $/ \mathrm{ml}$ in 6-well plates) containing fetal bovine serum (FBS) 
$(10 \%)$. L-arginine was added to the medium in the concentrations shown for each experiment. Cells were allowed to adhere for $2 \mathrm{hr}$, then stimulated by incubation with LPS $(100 \mathrm{ng} / \mathrm{ml})$ and IFN $\gamma(25 \mathrm{U} / \mathrm{ml})$. Total nitrite concentration in conditioned media was determined at the time points indicated. Aliquots of conditioned media $(200 \mu \mathrm{l})$ were assayed in triplicate for nitrite content by the Greiss method using dilutions of $\mathrm{NaNO}_{2}$ as a standard (17). Standard curves obtained in the presence and absence of CNI-1493 were indistinguishable, indicating that CNI-1493 did not interfere with the Greiss method.

\section{Determination of L-Arginine Uptake in RAW 264.7 Cells}

L-arginine uptake was measured by the method of Bogle and others (18). Briefly, RAW 264.7 cells were plated $\left(1 \times 10^{5}\right.$ cells/well $)$ in RPMI (with $10 \%$ FBS) in 96-well plates, allowed to adhere for $2 \mathrm{hr}$, then stimulated by the addition of rm-interferon- $\gamma(\mathrm{rm}-\mathrm{IFN} \gamma)(25 \mathrm{U} / \mathrm{ml}$; Genzyme) and LPS (Escherichia coli $0111: \mathrm{B} 4,100 \mathrm{ng} /$ ml; Sigma Chemical Co., St. Louis, MO, U.S.A.). At the times indicated after addition of stimulating agents, the cells were washed twice with HEPES-buffered Krebs solution containing $\mathrm{NaCl}$ (131 mM), $\mathrm{KCl}(5.5 \mathrm{mM}), \mathrm{MgCl}_{2}(1 \mathrm{mM}), \mathrm{CaCl}_{2}$ (2.5 mM), $\mathrm{NaHCO}_{3}(25 \mathrm{mM}), \mathrm{NaH}_{2} \mathrm{PO}_{4}(1 \mathrm{mM})$, D-glucose $(5.5 \mathrm{mM})$, and HEPES $(20 \mathrm{mM}), \mathrm{pH}$ $7.4,37^{\circ} \mathrm{C}$. In separate experiments, CNI- 1493 was supplied at the concentrations shown either $\mathrm{l} \mathrm{hr}$ before the cells were stimulated (preactivation), or $8 \mathrm{hr}$ after the cells were stimulated (postactivation). In both cases, CNI-1493 was added to the above buffer and cells incubated for $10 \mathrm{~min}$ at $37^{\circ} \mathrm{C}$ in the presence of $\mathrm{L}$-arginine $(100 \mu \mathrm{M}) ; \mathrm{L}-\left[2,3-{ }^{3} \mathrm{H}\right]$-arginine $(35 \mathrm{Ci} / \mathrm{mmol})$ was then added to each well, and after $5 \mathrm{~min}$ the cells were washed three times with ice-cold PBS, solubilized in formic acid (100 $\mu \mathrm{l})$, and the incorporated radioactivity determined by liquid scintillation counting. In other experiments and in agreement with previous reports, $\left[{ }^{3} \mathrm{H}\right]$-L-arginine transport in macrophages was observed to be linear for $10 \mathrm{~min}(18,19)$. In some experiments the efficiency of the washing step was verified by quantitative recovery of $D-\left[{ }^{14} \mathrm{C}\right] \mathrm{man}$ nitol included as an extracellular tracer (18). There was no significant efflux of transported label into the washes (not shown). In agreement with other studies in macrophages, $85 \%$ of Larginine is metabolized via arginase to ornithine and urea, and the remaining $15 \%$ via NOS to NO and citrulline (17).

\section{Determination of NOS Activity in Stimulated Macrophage Lysates}

Activity of NOS present in activated macrophage lysates was measured by determining the conversion of radiolabeled L-arginine into citrulline by a modification of previously described methods (20). Briefly, macrophages were stimulated with IFN $\gamma$ and LPS (as outlined above). After 18 $\mathrm{hr}$, the cells were washed with PBS and lysed by three cycles of freeze/thawing in HEPES (20 $\mathrm{mM})$ containing sucrose $(0.32 \mathrm{M})$, EDTA (1 $\mathrm{mM})$, DTT (1 $\mathrm{mM})$, glycerol $(5 \%)$, protease inhibitors (PMSF, leupeptin, aprotinin, and iodoacetamide), $\mathrm{pH}$ 7.2. The lysate was pelleted by centrifugation $(100,000 \times \mathrm{g})$ for $30 \mathrm{~min}$. To measure NOS activity in the lysates, $300 \mu \mathrm{l}$ of lysate was added to $60 \mu \mathrm{l}$ of a reaction mixture containing NADPH $(2 \mathrm{mM}), \mathrm{CaCl}_{2}(0.45 \mathrm{mM})$, Larginine $(50 \mu \mathrm{M})$, calmodulin $(10 \mu \mathrm{g} / \mathrm{ml}),\left[{ }^{3} \mathrm{H}\right]-$ L-arginine $(1 \mu \mathrm{Ci} / \mathrm{ml})$, and Tween $(20 \%)$. After $45 \mathrm{~min}$ at $37^{\circ} \mathrm{C}$ HEPES buffer $(2 \mathrm{ml})$ was added and the labeled L-arginine and citrulline separated by chromatography (DOWEX AS 50W column). NOS activity is expressed as nanomole citrulline per minute per milligram total protein.

\section{Determination of EDRF Activity In Vivo}

Female Sprague-Dawley rats (225-250 g body wt) were anesthetized with nembutal $(50 \mathrm{mg} / \mathrm{kg}$, i.p.), a tracheostomy tube inserted, and the carotid artery and jugular vein cannulated by standard methods using polyethylene tubing (PE 50) (21). Blood pressure was recorded continuously with a pressure transducer and recorder (Model RS-3200; Gould, Inc.). In the experiment shown here, animals received a single sterile intra-arterial dose of either $\mathrm{N}^{\mathrm{G}}$-methyl-L-arginine $(50 \mathrm{mg}$ / $\mathrm{kg}$; Sigma), CNI-1493 (10 mg/kg), or vehicle $(0.4$ $\mathrm{ml})$. Acetylcholine diluted in LPS-free sterile water was administered via the jugular vein cannula at the doses indicated. The solutions were diluted to provide a constant injectable volume of $1 \mathrm{ml} / \mathrm{kg}$ body wt. The hypotensive (EDRF) response was measured as the decline in mean arterial blood pressure recorded $30 \mathrm{sec}$ after administration of acetylcholine. The number of animals studied at each dose of acetylcholine was four to six for each experimental condition. The data are expressed as the mean \pm standard error. 


\section{Carrageenan-Induced Footpad Inflammation}

Paw edema was induced by injecting $1 \%$ Lambda-carrageenan (50 $\mu$ l; Sigma) in HEPES $25 \mathrm{mM}$, $\mathrm{pH} 7.4$, into the plantar surface of the left hindpaw of female $\mathrm{C} 3 \mathrm{H} / \mathrm{HeN}$ mice $(20-25 \mathrm{~g}$ body $\mathrm{wt})$ (22). The right hindpaw was injected with HEPES alone $(50 \mu \mathrm{l})$. At $1.5 \mathrm{hr}$ prior to paw injection, CNI-1493 was administered intraperitonealy at the doses indicated in a volume of 0.2 $\mathrm{ml} / \mathrm{animal}$. Three hours after paw injection, the thickness of the carrageenan- and saline-injected paws was measured using a caliper, and the data expressed as the difference between the diameters of the two paws. Data shown are the mean \pm standard error of the differences between paws; four animals were studied per dose of CNI-1493. At the conclusion of the experimental period, animals were euthanized and the paw tissues fixed with $10 \%$ formalin, sectioned, and stained with hematoxylin and eosin for histological study.

\section{Endotoxin Lethality Studies}

These studies were performed by modification of a recently published protocol (23). Briefly, BALB/c mice $(19-21 \mathrm{~g})$ were housed in a climate-controlled, 12-hr light-dark cycled facility for at least 2 weeks after arrival. On the morning of the experiment, mice were given either CNI1493 ( $1 \mathrm{mg} / \mathrm{kg}$, i.p.), $\mathrm{N}^{\mathrm{G}}$-methyl-L-arginine (50 $\mathrm{mg} / \mathrm{kg}$, i.p.), or vehicle alone. LPS (E. coli 0111 : B4; Sigma) in a dose of $13.75 \mathrm{mg} / \mathrm{kg}$, i.p. $(0.2$ $\mathrm{ml} / \mathrm{mouse}$ ) was given $90 \mathrm{~min}$ after the experimental agents. Stock LPS solutions $(10 \mathrm{mg} / \mathrm{ml})$ were sonicated initially for $20 \mathrm{~min}$, diluted in LPS-free water $(1.375 \mathrm{mg} / \mathrm{ml})$, then sonicated again for $10 \mathrm{~min}$ immediately prior to injection. All experiments consisted of 10 animals per group, and similar results were obtained at least twice for each condition.

\section{RESULTS}

\section{Macrophages Rely on Extracellular L- Arginine as Substrate for NOS Synthase}

It is widely known that murine macrophages produce copious quantities of NO after stimulation with LPS and IFN $\gamma(17,24-28)$. In the present investigation, we used the murine macrophage-like cell line, RAW 264.7, stimulated by the addition of IFN $\gamma(25 \mathrm{U} / \mathrm{ml})$ and LPS (100

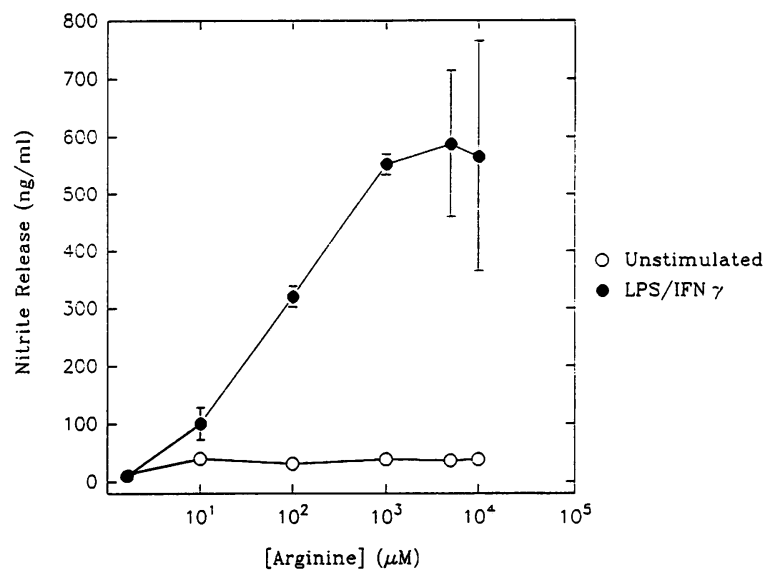

FIG. 1. Dependence of RAW cells on extracellular arginine to support NO production

RAW 264.7 cells were plated in RPMI devoid of Larginine or in RPMI supplemented with L-arginine as indicated, then stimulated by the addition of LPS $(100 \mathrm{ng} / \mathrm{ml})$ and IFN $\gamma(25 \mathrm{U} / \mathrm{ml})$ at time zero. Total nitrite accumulated in the medium conditioned by $1 \times 10^{6}$ cells over the subsequent $18 \mathrm{hr}$ is shown. Assays were performed in triplicate, and the experiment repeated at least three times. Data shown are mean $\pm \operatorname{SEM}(n=3$ experiments).

$\mathrm{ng} / \mathrm{ml}$ ) and measured the resultant cytokinestimulated NO production by the accumulation of nitrite in the conditioned medium. In agreement with others (17), we first ascertained that extracellular L-arginine availability was rate limiting for macrophage NO production (Fig. 1). Cytokine-stimulated macrophage NO production was significantly attenuated when the culture medium was depleted of L-arginine, but was restored when L-arginine was present at physiologically relevant concentrations $(50-150 \mu \mathrm{M})$ (Fig. 1). Although macrophages are known to possess the enzymatic machinery necessary to convert glutamine or citrulline into L-arginine for NO synthesis (29-36), the present data give evidence that macrophages rely principally on exogenous L-arginine to produce significant amounts of NO.

\section{Increased L-Arginine Transport in Activated Macrophages Provides Substrate for NOS}

In agreement with others $(18,19,33,35)$, we showed that macrophages activated by LPS/IFN $\gamma$ increase L-arginine uptake to provide substrate for NO production (Fig. 2). L-arginine transport in macrophages was increased shortly after mac- 


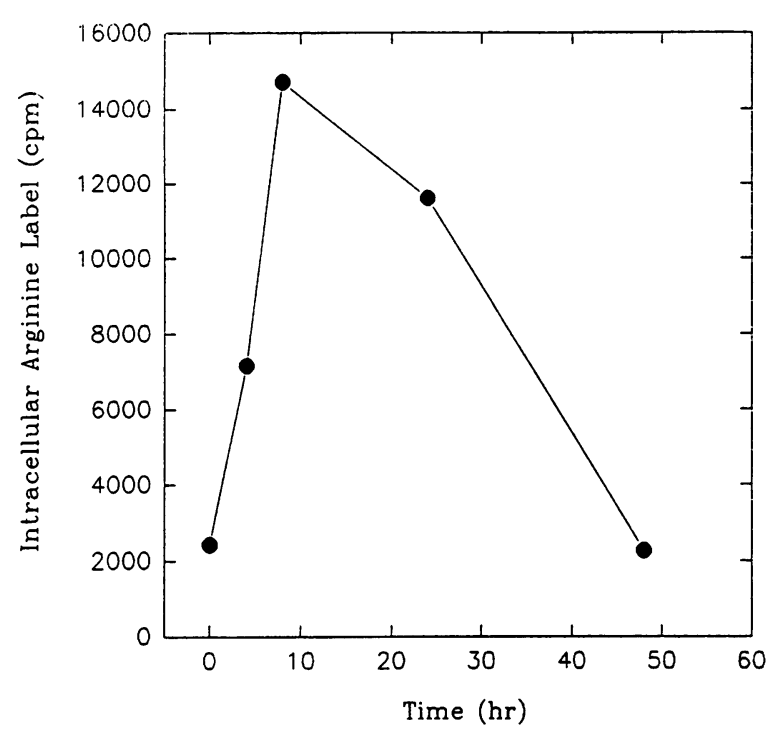

FIG. 2. Arginine transport is increased in activated RAW 264.7 cells

RAW cells were plated and activated with LPS and IFN $\gamma$ at $t=0$; and, at the times indicated, after addition of stimulating agents, the cells were washed, then incubated with $\mathrm{L}-\left[2,3-{ }^{3} \mathrm{H}\right]$-arginine $(1 \mu \mathrm{Ci} / \mathrm{ml}$, $69 \mathrm{Ci} / \mathrm{mg}, 0.025 \mu \mathrm{l} /$ well) with carrier L-arginine $(100 \mu \mathrm{M})$ at $37^{\circ} \mathrm{C}$. Data shown are the intracellular accumulation of label during the first 5 min after addition of tracer.

rophages were stimulated and remained elevated for more than $24 \mathrm{hr}$ (Fig. 2). Since exogenous L-arginine availability is rate limiting for macrophage NO production (above), and L-arginine transport is stimulated during macrophage activation, we reasoned that an inhibitor of L-arginine transport had the potential to inhibit macrophage NO production. Moreover, since endothelial cells are dependent upon neither extracellular Larginine nor L-arginine transport to produce NO $(29,30)$, this strategy could be expected to selectively inhibit NO production in macrophages, while preserving endothelial NO production in blood vessels, measured as EDRF activity.

\section{Development of a Novel Compound (CNI-1493) That Inhibits Cytokine- Inducible L-Arginine Transport}

Reasoning that a bulky, polyvalent guanylhydrazone compounds might interfere with the function of L-arginine transporters, we designed and synthesized a candidate inhibitor of cytokineinducible L-arginine uptake that exploits the structural similarity between guanylhydrazone

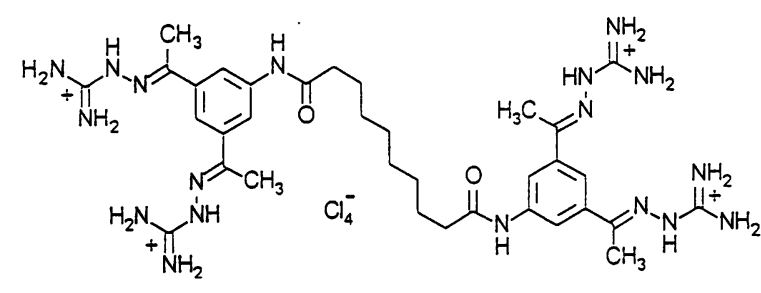

FIG. 3. Structure of CNI-1493

CNI-1493 (N,N' -bis[3,5-diacetylphenyl]decanediamide tetrakis[amidinohydrazone] tetrahydrochloride). Note the four guanidinium groups.

(more properly termed amidinohydrazone) functions and the guanidinium group of L-arginine (Fig. 3). This tetravalent guanylhydrazone compound, termed CNI-1493, inhibited cytokine-inducible L-arginine transport when added to the culture medium of macrophages that had been stimulated $8 \mathrm{hr}$ previously with LPS/IFN $\gamma$, and thus were activated to transport L-arginine (Fig. 4). There was a CNI-1493 dose-dependent inhibition of L-arginine transport; the I.C. ${ }_{50}$ of CNI-1493 against L-arginine transport in these postactivation experiments was $59 \pm 15 \mu \mathrm{M}$, a

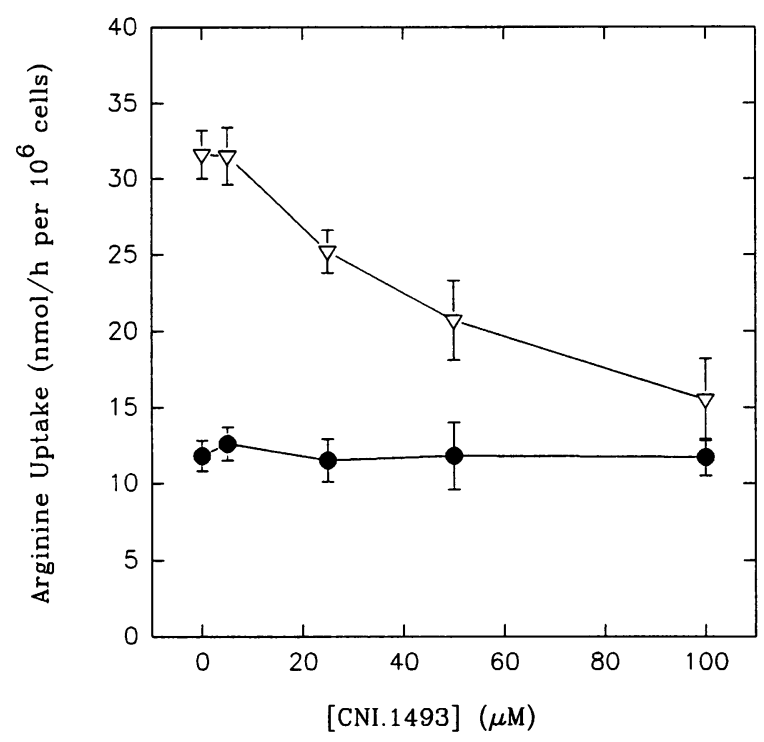

FIG. 4. CNI-1493 inhibits cytokine-inducible L-arginine transport in activated RAW cells In this postactivation experiment, CNI-1493 was added to cells that had been stimulated $8 \mathrm{hr}$ previously. The control, unstimulated macrophages have low levels of basal L-arginine uptake (filled circles), whereas activation with LPS and IFN $\gamma$ stimulates L-arginine uptake (open triangles). CNI-1493 caused a dose-dependent inhibition of the cytokine-inducible component of L-arginine uptake. Data shown are $\mathrm{L}$-arginine uptake expressed in $\mathrm{nmol} / \mathrm{hr} / 10^{6}$ cells (mean \pm SEM, $n=3$ experiments). 


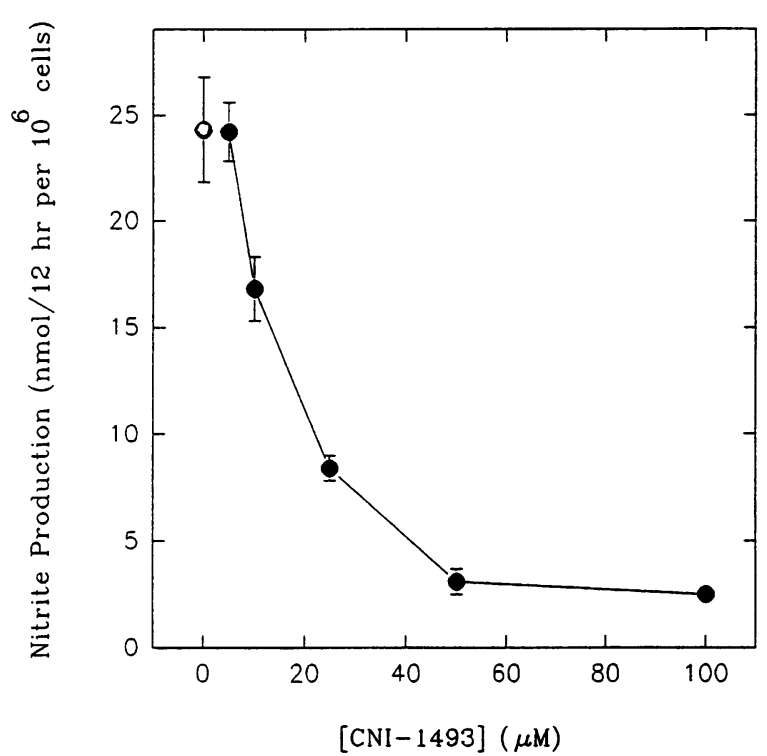

FIG. 5. CNI-1493 inhibits cytokine-inducible NO production in activated RAW cells

In this postactivation experiment, RAW 264.7 cells were stimulated for $8 \mathrm{hr}$ with LPS and IFN $\gamma$ as indicated, then the medium replaced, and CNI-1493 added to achieve the concentrations indicated for 4 hr. Nitrite production by these treated cells into fresh medium containing L-arginine $(100 \mu \mathrm{M})$ and CNI-1493 was measured for the subsequent $12 \mathrm{hr}$ period by assay for total nitrites accumulated in the culture medium. Data shown are nitrite production expressed in nmol/ $12 \mathrm{hr} / 10^{6}$ cells (mean $\pm \mathrm{SEM}$, $n=3$ experiments). Where the error bar is not visible, it lies within the extent of the symbol.

concentration at least 5 -fold lower than other known transport inhibitors such as L-lysine and L-ornithine (each about $350 \mu \mathrm{M}$ ) (18). Moreover, CNI-1493 did not inhibit basal, unstimulated L-arginine transport in resting macrophages, but was an effective inhibitor of cytokine-inducible L-arginine transport (Fig. 4). This provides evidence that CNI-1493 defines a functionally distinct class of transporters for L-arginine uptake in cytokine-activated macrophages.

\section{CNI-1493 Inhibits NO Production in Macrophages}

CNI-1493 effectively suppressed NO production in macrophages that had been previously activated with LPS/IFN $\gamma$ (Fig. 5). In the absence of CNI-1493, control cultures produced significant quantities of NO estimated by measuring nitrite accumulation during a 12 -hr period $(24.3 \pm 2.5$ $\mathrm{nmol} / 12 \mathrm{hr} / 10^{6}$ cells). Addition of CNI-1493 to the cultures suppressed the production of nitrites over the same period. The inhibitory effect of CNI-1493 on macrophage NO production was dose-dependent; the I.C.50 for CNI-1493 as an inhibitor of NO production by previously activated macrophages in these postactivation experiments was $20 \pm 2 \mu \mathrm{M}$. This concentration is comparable to the estimated I.C. ${ }_{50}$ of L-NMA and L-NAME (15-25 $\mu \mathrm{M})$ as inhibitors of macrophage NO production in our experiments (not shown) and previous reports $(37,38)$.

\section{CNI-1493 Prevents Macrophage Activation}

During the course of a mammalian infection, individual macrophages are stimulated to become activated at different times, so at any instant there are functionally distinct macrophage populations that are either quiescent, primed, or already activated. To evaluate the effects of CNI1493 in preventing induction of L-arginine transporters in macrophages that have not yet been stimulated, the inhibitor was added to quiescent macrophages $1 \mathrm{hr}$ before the addition of LPS and IFN $\gamma$, and L-arginine uptake measured 8 $\mathrm{hr}$ later. In the presence of typical plasma concentrations of L-arginine $(100 \mu \mathrm{M}), \mathrm{CNI}-1493$ $(7.5 \mu \mathrm{M})$ reduced L-arginine uptake to $53 \%$ of control values $\left(19.4 \pm 1.8 \mathrm{nmol} / 18 \mathrm{hr} / 10^{6}\right.$ cell versus $36.2 \pm 1.9 \mathrm{nmol} / 18 \mathrm{hr} / 10^{6}$ cell in controls). CNI-1493 also prevented cytokine-inducible NO production (measured as nitrite accumulation) in this preactivation model (Fig. 6). This inhibitory effect of CNI-1493 on NO production was partially competed by increasing concentrations of L-arginine in the medium. The I.C. ${ }_{50}$ for CNI-1493 in preventing cytokine-inducible NO production by pretreating quiescent macrophages was $4 \pm 1 \mu \mathrm{M}$ (extracellular L-arginine concentration $=100 \mu \mathrm{M})$. This result indicates that CNI-1493 is significantly more effective in preventing the induction of cytokine-mediated NO production in quiescent macrophages than in reversing an ongoing NO response in macrophages that previously had been activated.

\section{CNI-1493 Is Not a Direct NOS Inhibitor}

The goal of these studies was to develop an inhibitor of macrophage NO production that would confer a survival advantage in endotoxic shock. To be beneficial, a candidate inhibitor of NO production should work effectively in macrophages, yet inhibit neither NOS activity in vitro (because this enzyme activity is required to gen- 


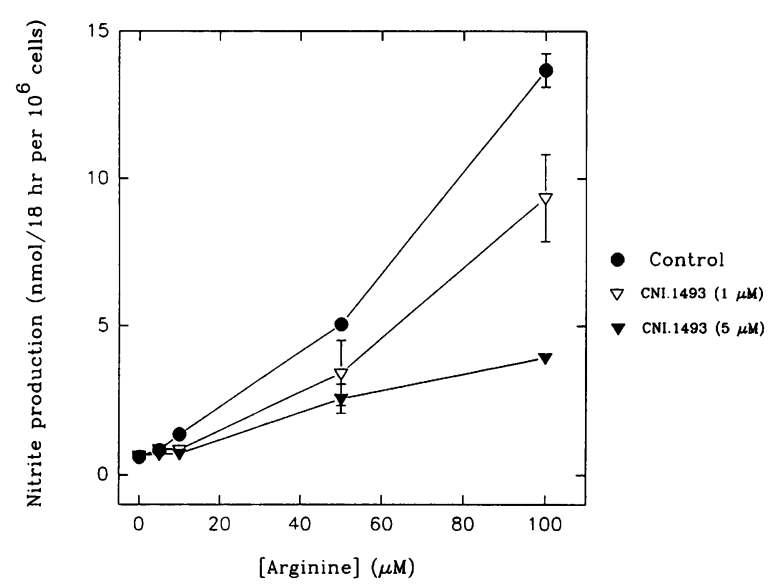

FIG. 6. Pretreatment with CNI-1493 prevents cytokine-inducible NO production in quiescent RAW cells

In this preactivation experiment, there was a dosedependent inhibition of nitrite production by addition of CNI-1493 at either $1 \mu \mathrm{M}$ (open triangles) or $5 \mu \mathrm{M}$ (closed triangles). Note that the inhibitory activity of CNI-1493 competes with increasing L-arginine concentration in the medium.

erate EDRF activity), nor EDRF responses measured in vivo. To examine the direct effect of CNI-1493 on NOS activity, we prepared lysates of RAW 264.7 cells that had been stimulated with LPS and IFN $\gamma$ for $8 \mathrm{hr}$. As a positive control, the competitive substrate inhibitor of NOS, L-NMA ( $1 \mathrm{mM}$ added to cell lysate preparations) was observed to completely suppress NOS activity measured by conversion of arginine into citrulline (L-NMA treated $=0.005 \mathrm{nmol} / \mathrm{mg} / \mathrm{min}$ versus control $=0.058 \mathrm{nmol} / \mathrm{mg} / \mathrm{min})$. By contrast, CNI-1493 $(50 \mu \mathrm{M})$ in macrophage lysates did not inhibit NOS $(0.058 \mathrm{nmol} / \mathrm{mg} / \mathrm{min})$, suggesting that CNI-1493 does not function as a direct antagonist of NOS enzyme activity. When considered together, these data give strong evidence that CNI-1493 inhibits NO production in cytokine-activated macrophages by interfering with the activation-specific increase in uptake of L-arginine (which is normally required to support macrophage NO production), not by inhibiting NOS directly.

\section{CNI-1493 Preserves Blood Vessel Endothelial-Derived Relaxing Factor Activity}

The goal of these studies was to develop an agent that would effectively inhibit NO synthesis by

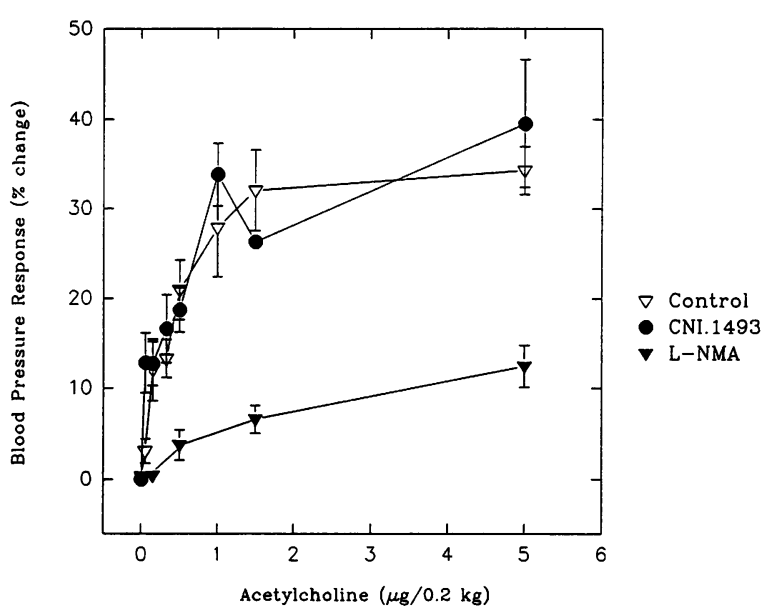

FIG. 7. CNI-1493 does not inhibit EDRF activity

Note that the normal response to increasing doses of the EDRF-dependent drug acetylcholine is an increasing blood pressure response (controls). In agreement with previously published work, pretreatment with L-NMA (positive controls) blunts EDRF activity. This stands in contrast to animals pretreated with CNI-1493, which manifest normal EDRF responses following acetylcholine challenge.

activated macrophages but not inhibit the activity of endothelial-derived relaxing factor (EDRF) in vivo. We next examined the effect of CNI1493 on EDRF responses in an in vivo animal model (Fig. 7). Blood pressure responses to acetylcholine (an EDRF-dependent vasodilator) were measured continuously in pentobarbital-anesthetized rats before, during, and after administration of CNI-1493, L-NMA, or vehicle only. As expected from previously published data (39), the EDRF response was inhibited by L-NMA, as evidenced by attenuated blood pressure responses in L-NMAtreated animals compared with vehicle-treated controls (Fig. 7). Moreover, in agreement with its known vasoconstrictive properties, we observed that L-NMA caused transient hypertension (data not shown) $(13,39,40)$. In contrast, CNI-1493 did not suppress acetylcholine-induced blood pressure changes or cause hypertension (Fig. 7).

\section{CNI-1493 Prevents Carrageenan-Induced Inflammation}

The effectiveness of CNI-1493 in suppressing NO production while preserving EDRF activity prompted us to test its effects in murine models of inflammation. We first utilized a carrageenaninduced paw edema model that has been used 


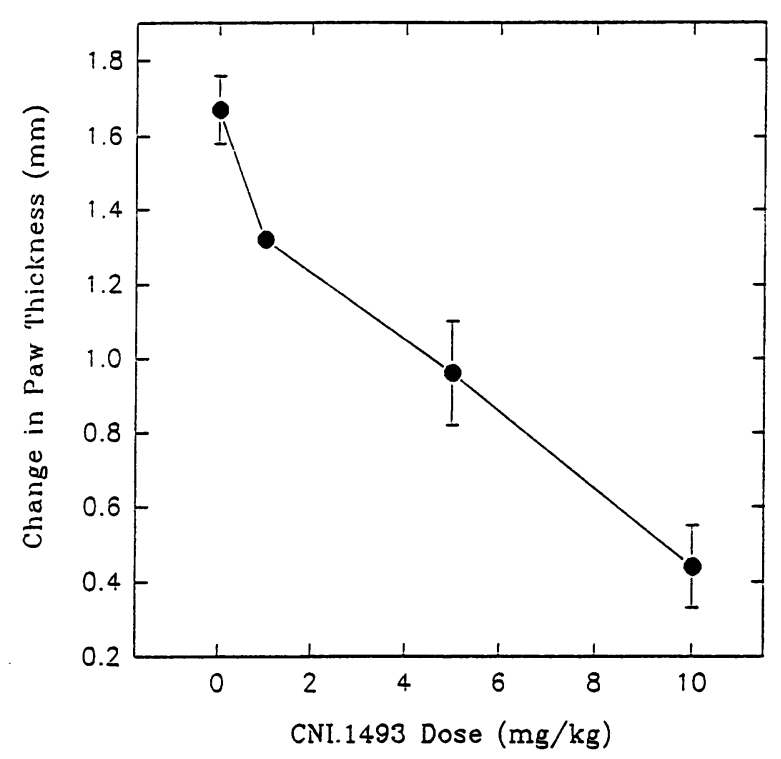

FIG. 8. CNI-1493 suppresses carrageenaninduced paw edema

CNI-1493 was administered intraperitoneally, and 90 min later carrageenan was injected into the footpad. The data shown are the changes in footpad thickness between the carrageenan-injected and the vehicleinjected footpad after $3 \mathrm{hr}$. The results shown are from a representative experiment; this experiment was repeated at least three times $(n=6$ animals per dose).

for more than 30 years as a screening assay for the development of anti-inflammatory compounds (22). Mice received injections of carrageenan into the right hind paw and saline vehicle alone into the left paw. The inflammatory response to carrageenan caused significant paw swelling within $3 \mathrm{hr}$ in controls as measured by an increase in the diameter of the carrageenaninjected footpad (Fig. 8). CNI-1493 administered intraperitoneally at various doses (Fig. 8) prevented the development of carrageenan-induced paw swelling. Histological examination of carrageenan-inflamed paw tissue revealed marked subcutaneous edema and moderate to severe neutrophil infiltration (Fig. $9 \mathrm{a}$ and b). Polymorphonuclear leukocytes were observed to be marginated around dilated capillaries in the soft tissues. CNI-1493 conferred significant protection against the development of this subcutaneous edema and neutrophil recruitment (Fig. $9 \mathrm{c}$ and d). These results give evidence that, in doses that are comparable to other widely used anti-inflammatory agents (e.g., the therapeutic doses of acetaminophen and ibuprofen in humans are between 10 and $15 \mathrm{mg} / \mathrm{kg}$ ), CNI-1493 prevents inflammation.
Further evidence implicating NO as a mediator of edema in this model was obtained by administering S-nitro- $\mathrm{N}$-acetyl-penicillamine (SNAP) directly into the footpad. SNAP is a chemical precursor of NO that decomposes to NO and $\mathrm{N}$-acetyl-penicillamine. SNAP injected directly into foot pads $(0.5 \mathrm{mg} / 50 \mu \mathrm{l} / \mathrm{paw})$ caused significant subcutaneous edema within $3 \mathrm{hr}$ $(1.0+0.09 \mathrm{~mm})$; but controls that received $\mathrm{N}$ acetyl-penicillamine did not develop edema $(0.03 \pm 0.035 \mathrm{~mm})$ as measured by paw swelling.

To test whether CNI-1493 inhibited macrophage NO production in vivo, the agent $(0.4$ $\mathrm{mg} / \mathrm{kg}$, i.p.) or vehicle alone was administered to $\mathrm{BALB} / \mathrm{c}$ mice, and peritoneal macrophages isolated by lavage $2 \mathrm{hr}$ later. Upon subsequent LPS/ IFN $\gamma$ treatment in vitro, NO production over 18 hr was attenuated $76 \%$ in macrophages obtained from CNI-1493-treated animals (NO production in controls $=28 \pm 4 \mathrm{nmol} / 1 \times 10^{6}$ cells versus CNI- 1493 treated $=7 \pm 2 \mathrm{nmol} / 1 \times 10^{6}$ cells). Considered together, these results indicate that CNI-1493 is effective in preventing carrageenaninduced inflammation and NO production by macrophages in vivo.

\section{CNI-1493 Confers Survival Advantage Against Endotoxin Lethality}

The development and characterization of CNI1493 in these experiments enabled us to next address the central hypothesis: an inhibitor of macrophage NO production that preserves EDRF responses can protect against the lethal toxicity of LPS in vivo. Accordingly, we utilized a murine model of endotoxemia to evaluate the effect of CNI-1493 in preventing lethal toxicity (Fig. 10). Administration of CNI-1493 (l $\mathrm{mg} / \mathrm{kg}$ ) to $\mathrm{BALB} / \mathrm{c}$ mice $1.5 \mathrm{hr}$ before LPS challenge (at an L.D. 50 dose) increased survival from $50 \%$ for vehicle-treated controls to $90 \%$ for the CNI1493-treated group $(p<0.05)$. In agreement with previous observations, administration of L-NMA $1.5 \mathrm{hr}$ before LPS challenge decreased survival to only $10 \%(p<0.05)$. Controls receiving LPS and vehicle, and animals treated with LPS and L-NMA, were unkempt, showed decreased spontaneous movement about the cage, and huddled together; these visible signs of LPS toxicity were also markedly suppressed by administration of CNI-1493. Diarrhea occurred in all animals and was not suppressed by CNI-1493. These data indicate that an inhibitor of L-arginine transport that preserves EDRF activity is protective against LPS lethality. 


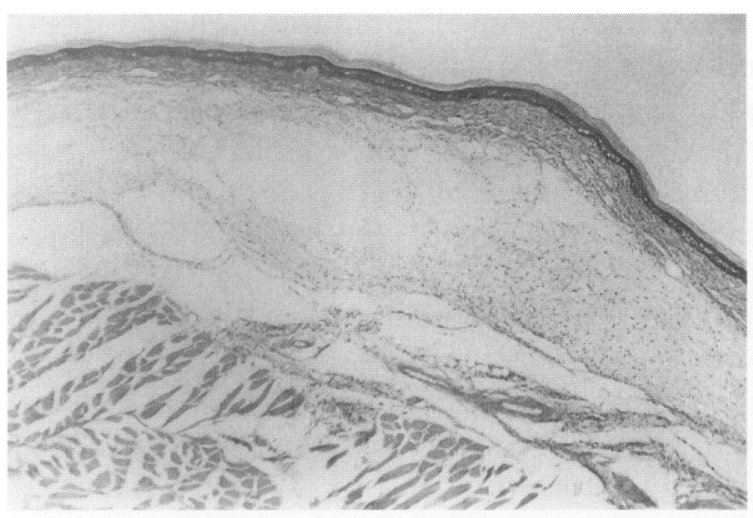

a b
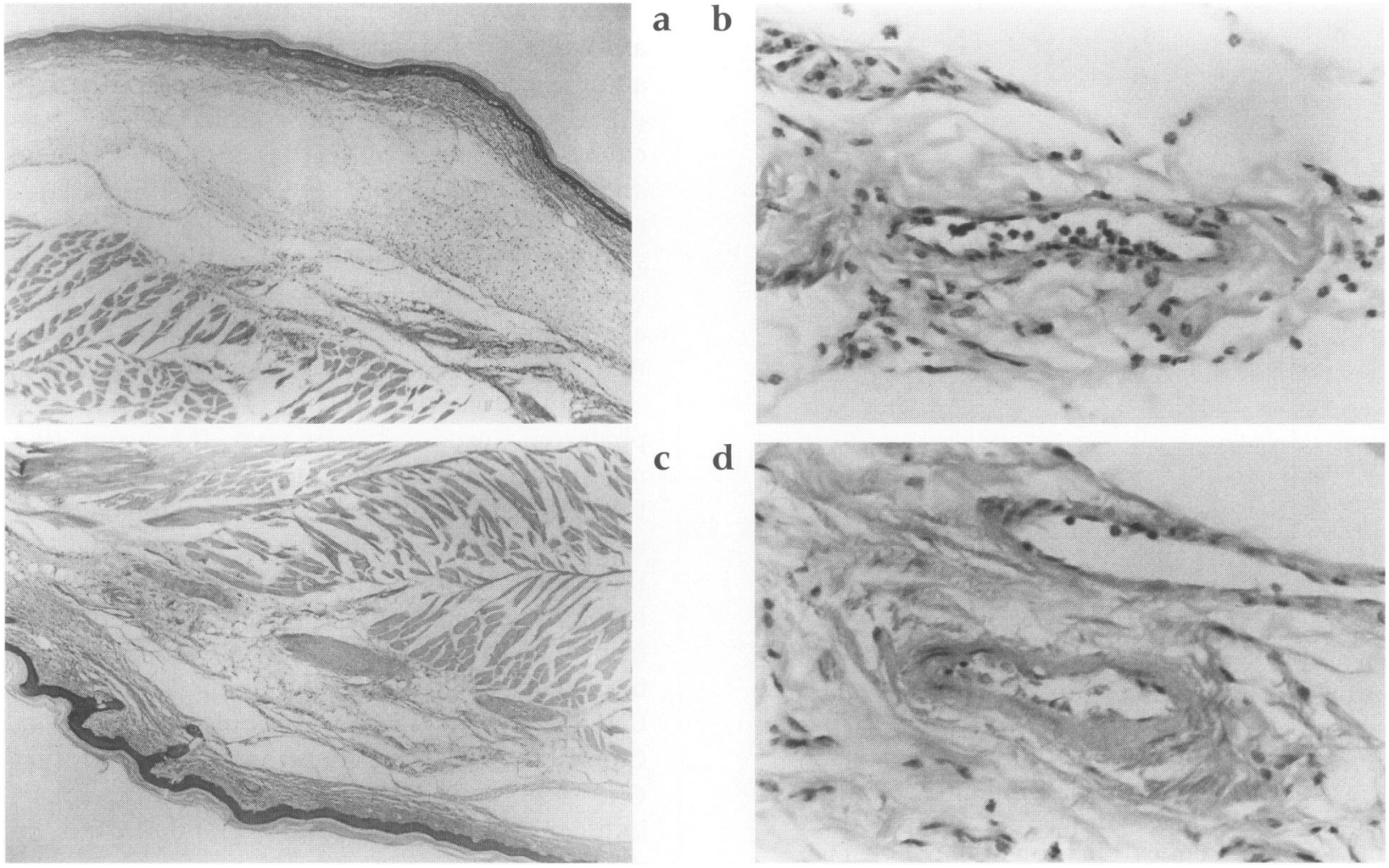

c d

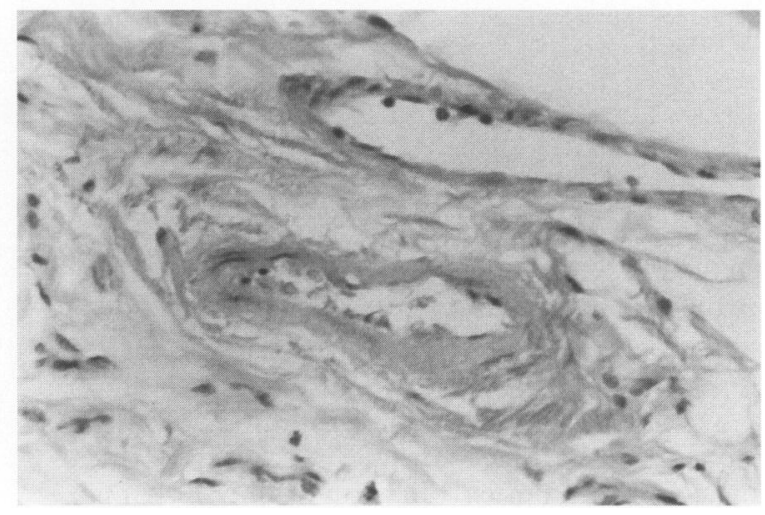

FIG. 9. Histological appearance of paw tissues obtained from the carrageenan-injected paw

Three hours after carrageenan administration, paw tissues were fixed with $10 \%$ formalin, and sections were stained with hematoxylin and eosin. ( $a$ and $b$ ) Sections taken from the carrageenan-treated footpad of a control animal not receiving CNI-1493. (a) A low power panoramic view; (b) a high power view of the same tissue showing neutrophil margination in a dilated capillary. ( $c$ and d) Comparable sections taken from the carrageenantreated footpad of an animal treated with CNI-1493 (10 mg/kg, i.p.).

\section{DISCUSSION}

These studies give direct evidence that a novel compound (CNI-1493) that inhibits cytokine-inducible L-arginine transport in macrophages is effective in preventing NO production, carrageenan-induced inflammation and LPS lethality. To our knowledge, this is the first compound to target macrophage NO production but preserve EDRF activity in blood vessels, thereby offering protection against lethal endotoxic shock and organ damage.

\section{CNI-1493 Prevents Macrophage Activation}

An unexpected but important finding from these experiments is our observation that CNI-1493 is an extremely potent inhibitor of LPS-induced activation of macrophages. These results are somewhat analogous to the actions of glucocorticoids, which effectively prevent macrophage activation when administered before LPS (as measured by NO production), and prevent both carrageenan-induced inflammation and LPS lethality. While the present data give direct evidence that CNI-1493 is an inhibitor of cytokineinducible $\mathrm{L}$-arginine transport in macrophages, it is unclear whether its effect as a transport inhibitor accounts directly for its suppression of macrophage activation. The cytokine-inducible L-arginine transporter in macrophages has been identified as MCAT-2b (41), and it is plausible that CNI-1493 pretreatment may inhibit the earliest population of MCAT-2b transporters to be induced following cytokine treatment. This early interference might, in turn, interrupt any NOdependent "feed forward" signals controlling further up-regulation of the cytokine-inducible component of arginine transport and thus potently inhibit total NO production. Another possibility is that CNI-1493 acts at another site in the signaling process of macrophage activation, perhaps by down-regulating cytokine production. 


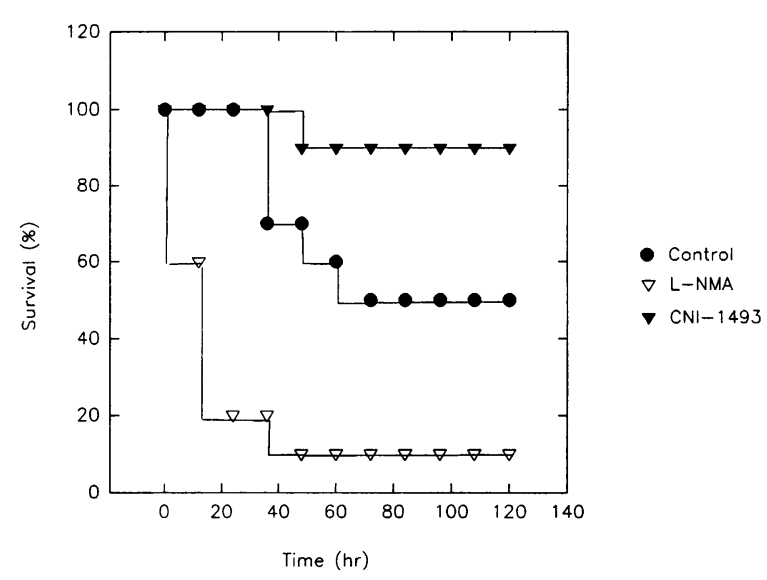

FIG. 10. CNI-1493 protects against LPSinduced lethality

All animals received an L.D. ${ }_{50}$ dose of $E$. coli 0111:B4 LPS (13.75 mg/kg). Note that L-NMA significantly decreased survival, but CNI-1493 significantly improved survival. Each group consisted of 10 mice; differences between CNI-1493 and controls, and between L-NMA and controls, are statistically significant $(p<0.05$ by the two-tailed Fisher's exact test).

This possibility is particularly intriguing, and probably unique, since other known inhibitors of L-arginine transport (e.g., lysine and ornithine) are ineffective in preventing macrophage activation as measured by NO production, with estimated I.C. 50 in the range of $10 \mathrm{mM}$ (18). Albina and coworkers have previously reported that arginine availability directly influences macrophage function (42). The availability of a potent inhibitor of L-arginine uptake (CNI-1493) may now prove useful in delineating the functional role of cytokine-inducible L-arginine transporters (MCAT-2b) and L-arginine availability in the biology of macrophage activation.

\section{Anti-Inflammatory Effects of CNI-1493}

The macrophage occupies a paradoxical role in defense against invasion or infection because once unleashed, its armamentarium may indiscriminately injure tissues and kill the very host it evolved to protect $(1,21,43,44)$. Novel therapeutic strategies designed to specifically prevent this "collateral damage" during inflammation are at all stages of preclinical testing and clinical use. Since CNI-1493 prevents carrageenan-induced inflammation, it seems likely that it acts to effectively interrupt the mediator cascade that normally recruits inflammatory cells, and also pre- vents the release of toxic products that injure tissues. Nonselective inhibitors of NOS (e.g., L-NMA and L-NAME) are protective against carrageenan-induced inflammation when co-injected directly in the paw (45), but are relatively ineffective in preventing acute edema formation when given systemically (46). When considered together with the present data, it is likely that inhibiting NO locally in the paw accounts (at least partially) for the beneficial activity of CNI1493 in carrageenan-induced inflammation.

\section{CNI-1493 in Endotoxic Shock}

The development of a pharmacological inhibitor of macrophage arginine transport should prove useful in further delineating specific details of macrophage function in endotoxin and septic shock states. The unique actions of CNI-1493 in preventing both macrophage NO production and LPS lethality differ significantly from nonselective NOS inhibitors. For instance, evidence obtained with human immune cells indicates that NO participates in the regulation of the synthesis of TNF and other cytokines (47). The principal mediator of LPS toxicity is TNF, and, when coupled with the loss of organ perfusion resulting from the nonselective NOS inhibitors, the increased lethality resulting from administration of unspecific NOS inhibitors is not surprising $(2,10-$ $14,21,44,48)$. It will be of interest now to examine directly the influence of systemically administered CNI-1493 on the cytokine response in LPStreated animals, and in human immunocytes.

\section{CONCLUSION}

We have developed a selective inhibitor of cytokine-inducible L-arginine transport (CNI-1493) that effectively inhibits NO production by activated macrophages. In contrast to previously available NO inhibitors, this agent does not inhibit NOS directly, and preserves EDRF activity in blood vessels. When administered in vivo, CNI-1493 is effective against endotoxin lethality and carrageenan inflammation. These studies indicate that it is feasible to develop novel therapeutics for inflammation and septic shock syndrome by selective inhibition of cytokine-inducible L-arginine transporter function in activated macrophages. 


\section{ACKNOWLEDGMENTS}

This work was supported in part by National Institutes of Health Grant ROIDK49283 (KT), a Faculty Fellowship Award from the American College of Surgeons (KT), a grant from Cytokine Network Inc., and Institutional Funding from the Picower Institute.

\section{REFERENCES}

1. Tracey KJ. (1991) Tumor necrosis factor (cachectin) in the biology of septic shock syndrome. Circ. Shock 35: 123-128.

2. Tracey KJ, Lowry SF. (1990) The role of cytokine mediators in septic shock. Adv. Surg. 23: 21-56.

3. Bredt DS, Snyder SH. (1994) Nitric oxide: A physiologic messenger molecule. Ann. Rev. Biochem. 63: 175-195.

4. Geller DA, Nussler AK, DiSilvio $M$, et al. (1993) Cytokines, endotoxin, and glucocorticoids regulate the expression of inducible nitric oxide synthase in hepatocytes. Proc. Natl. Acad. Sci. U.S.A. 90: 522-526.

5. Tracey KJ, Vlassara H, Cerami A. (1989) Cachectin/TNF (tumour necrosis factor). Lancet 1: 1122-1126.

6. Moncada S, Higgs A. (1993) The L-argininenitric oxide pathway. $N$. Engl. J. Med. 329: 2001-2012.

7. Nathan C. (1992) Nitric oxide as a secretory product of mammalian cells. F.A.S.E.B. J. 6: 3051-3064.

8. Weinberg JB, Granger DL, Pisetsky DS, et al. (1994) The role of nitric oxide in the pathogenesis of spontaneous murine autoimmune disease: Increased nitric oxide production and nitric oxide synthase expression in MRL-lpr/lpr mice, and reduction of spontaneous glomerulonephritis and arthritis by orally administered $\mathrm{N}^{\mathrm{G}}$-monomethyl-L-arginine. J. Exp. Med. 179: 651-660.

9. McCartney-Francis N, Allen JB, Mizel DE, et al. (1993) Suppression of arthritis by an inhibitor of nitric oxide synthase. J. Exp. Med. 178: $749-754$.

10. Billiar TR, Curran RD, Harbrecht BG, Steuhr DJ, Demetris AJ, Simmons RL. (1990) Modulation of nitrogen oxide synthesis in vivo: $\mathrm{N}^{\mathrm{G}}$ monomethyl-L-arginine inhibits endotoxin-induced nitrite/nitrate biosynthesis while promoting hepatic damage. J. Leukocyte Biol. 48: 565-569.
11. Shultz PJ, Baij L. (1992) Endogenously synthesized nitric oxide prevents endotoxin-induced glomerular thrombosis. J. Clin. Invest. 90: 1718-1725.

12. Nava E, Palmer RMJ, Moncada S. (1991) Inhibition of nitric oxide synthesis in septic shock: how much is beneficial? Lancet 338: 1555-1557.

13. Cobb JP, Natanson C, Hoffman WD, et al. (1992) $\mathrm{N}^{\mathrm{G}}$-amino-L-arginine, an inhibitor of nitric oxide synthase, raises vascular resistance but increases mortality rates in awake canines challenged with endotoxin. J. Exp. Med. 176: 1175-1182.

14. Minnard EA, Shou J, Naama H, Cech A, Gallagher H, Daly JM. (1994) Inhibition of nitric oxide synthesis is detrimental during endotoxemia. Arch. Surg. 129: 142-148.

15. Statman R, Cheng W, Cunningham JN, et al. (1994) Nitric oxide inhibition in the treatment of the sepsis syndrome is detrimental to tissue oxygenation. J. Surg. Res. 57: 93-98.

16. Ulrich P, Cerami A. (1984) Trypanocidal 1,3arylene diketone bis(guanylhydrazone)s. Structure-activity relationships among substituted and heterocyclic analogues. J. Med. Chem. 27: 35-40.

17. Vodovotz Y, Kwon NS, Pospischil M, Manning J, Paik J, Nathan C. (1994) Inactivation of nitric oxide synthase after prolonged incubation of mouse macrophage with IFNgamma and bacterial lipopolysaccharide. $J$. Immunol. 152: 4110-4118.

18. Bogle RG, Baydoun AR, Pearson JD, Moncada S, Mann GE. (1992) L-arginine transport is increased in macrophages generating nitric oxide. Biochem. J. 284: 15-18.

19. Baydoun AR, Bogle RG, Pearson JD, Mann GE. (1993) Arginine uptake and metabolism in cultured murine macrophages. Agents Actions 38: C127-C129. Abstract.

20. Bredt DS, Hwang PM, Glatt CE, Lowenstein C, Reed RR, Snyder SH. (1991) Cloned and expressed nitric oxide synthase structurally resembles cytochrome $\mathrm{P}-450$ reductase. $\mathrm{Na}$ ture 351: 714-718.

21. Tracey KJ, Beutler B, Lowry SF, et al. (1986) Shock and tissue injury induced by recombinant human cachectin. Science 234: 470474.

22. Otterness IV, Moore PF. (1988) Carrageenan foot edema test. Methods Enzymol. 162: 320327.

23. Bernhagen J, Calandra T, Mitchell RA, et al. (1993) Macrophage migration inhibitory 
factor (MIF) is a pituitary-derived cytokine and potentiates lethal endotoxaemia. Nature 365: 756-769.

24. Ding AH, Nathan CF, Stuehr DJ. (1988) Release of reactive nitrogen intermediates and reactive oxygen intermediates from mouse peritoneal macrophages. J. Immunol. 141: 2407-2412.

25. Nussler AK, Billiar TR, Liu Z, Morris Jr SM. (1994) Coinduction of nitric oxide synthase and argininosuccinate synthetase in a murine macrophage cell line. J. Biochem. 269: 1257-1261.

26. Granger DL, Hibbs Jr JB, Perfect JR, Durack DT. (1990) Metabolic fate of L-arginine in relation to microbiostatic capability of murine macrophages. J. Clin. Invest. 85: 264273.

27. Hibbs Jr JB, Taintor RR, Vavrin Z. (1987) Macrophage cytotoxicity: Role for L-arginine deiminase and imino nitrogen oxidation to nitrite. Science 235: 473-476.

28. Granger DL, Taintor RR, Cook JL, Hibbs Jr JB. (1980) Injury of neoplastic cells by murine macrophages leads to inhibition of motochondrial respiration. J. Clin. Invest. 65: 357-370.

29. Sessa WC, Hecker M, Mitchell JA, Vane JR. (1990) The metabolism of L-arginine and its significance for the biosynthesis of endothelium-derived relaxing factor: L-glutamine inhibits the generation of L-arginine by cultured endothelial cells. Proc. Natl. Acad. Sci. U.S.A. 87: 8607-8611.

30. Hecker M, Sessa WC, Harris HJ, Anggard EE, Vane JR. (1990) The metabolism of L-arginine and its significance for the biosynthesis of endothelium-derived relaxing factor: Cultured endothelial cells recycle L-citrulline to L-arginine. Proc. Natl. Acad. Sci. U.S.A. 87: 8612-8616.

31. Nussler A, Billiar T, Liu Z, Morris S. (1994) Coinduction of nitric oxide synthase and argininosuccinate synthetase in a murine macrophage cell line. J. Biol. Chem. 269: 1257-1261.

32. Baydoun AR, Bogle RG, Pearson JD, Mann GE. (1994) Discrimination between citrulline and arginine transport in activated murine macrophages: Inefficient synthesis of NO from recycling of citrulline to arginine. Br. J. Pharmacol. 112: 487-492.

33. Hrabak A, Idei M, Temesi A. (1994) Arginine supply for nitric oxide synthesis and arginase is mainly exogenous in elicited murine and rat macrophages. Life Sci. 55: 797-805.

34. Wu G, Brosnan JT. (1992) Macrophages can convert citrulline into arginine. Biochem. Biophysical. Res. Commun. 281: 45-48.

35. Sato H, Fujiwara M, Bannai S. (1992) Effect of lipopolysaccharide on transport and metabolism of arginine in mouse peritoneal macrophages. J. Leukocyte Biol. 52: 161-164.

36. Mills CD, Shearer J, Evans R, Caldwell MD. (1992) Macrophage arginine metabolism and the inhibition of stimulation of cancer. $J$. Immunol. 149: 2709-2714.

37. Hasan K, Heesen BJ, Corbett JA, et al. (1993) Inhibition of nitric oxide formation by guanidines. Eur. J. Pharmacol. 249: 101106.

38. MacAllister RJ, Whitley GSJ, Vallance P. (1994) Effects of guanidino and uremic compounds on nitric oxide pathways. Kidney Int. 45: 737-742.

39. Kilbourn RG, Gross SS, Jubran A, et al. (1990) $\mathrm{N}^{\mathrm{g}}$-methyl-L-arginine inhibits tumor necrosis factor-induced hypotension: Implications for the involvement of nitric oxide. Proc. Natl. Acad. Sci. U.S.A. 87: 3629-3632.

40. Cobb JP, Cunnion RE, Danner RL. (1993) Nitric oxide as a target for therapy in septic shock. Crit. Care Med. 21: 1261-1263.

41. Closs EI, Lyons CR, Kelly C, Cunningham JM. (1993) Characterization of the third member of the MCAT family of cationic amino acid transporters. J. Biol. Chem. 268: 20796-20800.

42. Albina JA, Caldwell MD, Henry Jr WL, Mills CD. (1989) Regulation of macrophage functions by L-arginine. J. Exp. Med. 169: $1021-$ 1029.

43. Tracey KJ. (1992) The acute and chronic pathophysiological effects of TNF: Mediation of septic shock and wasting (cachexia). In: Beutler B (ed). Tumor Necrosis Factors: The Molecules and Their Emerging Role in Medicine. Raven Press, New York, pp. 255-273.

44. Tracey KJ, Fong Y, Hesse DG, et al. (1987) Anti-cachectin/TNF monoclonal antibodies prevent septic shock during lethal bacteraemia. Nature 330: 662-664.

45. Ialenti A, Ianaro A, Moncada S, DiRosa M. (1992) Modulation of acute inflammation by endogenous nitric oxide. Eur. J. Pharmacol. 211: 177-182.

46. Ianaro A, O'Donnell CA, Di Rosa M, Liew FY. (1994) A nitric oxide synthase inhibitor reduces inflammation, down-regulates in- 
flammatory cytokines and enhances interleukin-10 production in carrageenin-induced oedema in nice. Immunology 82: 370-375.

47. Van Dervort AL, Yan L, Madara PJ, et al. (1994) Nitric oxide regulates endotoxin-in- duced TNF-alpha production by human neutrophils. J. Immunol. 152: 4102-4109.

48. Tracey KJ, Cerami A. (1994) Tumor necrosis factor: A pleiotropic cytokine and therapeutic target. Annu. Rev. Med. 45: 491-503.

Contributed by A. Cerami on January 18, 1995. 